\title{
Dynamics of team cognition and team adaptation: Introduction to the special issue
}

Citation for published version (APA):

Gevers, J. M. P., Uitdewilligen, S., \& Passos, A. M. (2015). Dynamics of team cognition and team adaptation: Introduction to the special issue. European Journal of Work and Organizational Psychology, 24(5), 645-651. https://doi.org/10.1080/1359432x.2015.1065251

Document status and date:

Published: 01/01/2015

DOI:

10.1080/1359432x.2015.1065251

Document Version:

Publisher's PDF, also known as Version of record

Document license:

Taverne

Please check the document version of this publication:

- A submitted manuscript is the version of the article upon submission and before peer-review. There can be important differences between the submitted version and the official published version of record.

People interested in the research are advised to contact the author for the final version of the publication, or visit the DOI to the publisher's website.

- The final author version and the galley proof are versions of the publication after peer review.

- The final published version features the final layout of the paper including the volume, issue and page numbers.

Link to publication

\footnotetext{
General rights rights.

- You may freely distribute the URL identifying the publication in the public portal. please follow below link for the End User Agreement:

www.umlib.nl/taverne-license

Take down policy

If you believe that this document breaches copyright please contact us at:

repository@maastrichtuniversity.nl

providing details and we will investigate your claim.
}

Copyright and moral rights for the publications made accessible in the public portal are retained by the authors and/or other copyright owners and it is a condition of accessing publications that users recognise and abide by the legal requirements associated with these

- Users may download and print one copy of any publication from the public portal for the purpose of private study or research.

- You may not further distribute the material or use it for any profit-making activity or commercial gain

If the publication is distributed under the terms of Article $25 \mathrm{fa}$ of the Dutch Copyright Act, indicated by the "Taverne" license above, 


\title{
Dynamics of team cognition and team adaptation: Introduction to the special issue
}

\author{
Josette M. P. Gevers, Sjir Uitdewilligen \& Ana Margarida Passos
}

To cite this article: Josette M. P. Gevers, Sjir Uitdewilligen \& Ana Margarida Passos (2015) Dynamics of team cognition and team adaptation: Introduction to the special issue, European Journal of Work and Organizational Psychology, 24:5, 645-651, DOI: 10.1080/1359432X.2015.1065251

To link to this article: https://doi.org/10.1080/1359432X.2015.1065251

曲 Published online: 29 Jul 2015.

Submit your article to this journal $₫$

Џll Article views: 1679

Q View related articles $\sqsubset$

View Crossmark data \lceil

Citing articles: 4 View citing articles 


\title{
Dynamics of team cognition and team adaptation: Introduction to the special issue
}

\author{
Josette M. P. Gevers ${ }^{1}$, Sjir Uitdewilligen $\odot^{2}$, and Ana Margarida Passos $\circledast^{3}$ \\ ${ }^{1}$ Human Performance Management Group, Department of Industrial Engineering and Innovation Sciences, Eindhoven \\ University of Technology, Eindhoven, The Netherlands \\ ${ }^{2}$ Faculty of Psychology and Neuroscience, Department of Work and Social Psychology, Maastricht University, \\ Maastricht, The Netherlands \\ ${ }^{3}$ Business Research Unit (BRU-IUL), Instituto Universitário de Lisboa (ISCTE-IUL), Lisbon, Portugal
}

\begin{abstract}
Although cognitions are known to play a major role in team adaptation, the cognitive dynamics underlying a team's responsiveness are poorly understood. The studies brought together in this special issue break new ground in this area. In this introductory article, we offer a brief summary of the research field, provide an overview of the contributions, and suggest directions for future research.
\end{abstract}

Keywords: Team; Cognition; Adaptation; Dynamics.

Change is an ever-present reality in modern organizations. Being faced with higher levels of unpredictability, complexity, and turbulence, organizations increasingly rely on the ability of teams to effectively adapt to these changing circumstances for their survival. Although the body of knowledge concerning factors that impact team performance has increased tremendously over the last few decades (e.g., Kozlowski \& Ilgen, 2006; Mathieu, Maynard, Rapp, \& Gilson, 2008), relatively few studies specifically address how teams adapt to novel and challenging circumstances (LePine, 2005; Randall, Resick, \& DeChurch, 2011). Recent insights suggest that knowledge of the dynamic aspects of team cognition is quintessential to deepen our understanding of team adaptation (Burke, Stagl, Salas, Pierce, \& Kendall, 2006; DeChurch \& Mesmer-Magnus, 2010), as cognitive constructs such as shared mental models, team transactive memory, and team situation awareness enable teams to detect and manage unexpected events in their dynamic task environment. However, despite calls for a more dynamic approach (Kozlowski \& Chao, 2012; Rico, Sánchez-Manzanares, Gil, \& Gibson, 2008; Roe, Gockel, \& Meyer, 2012), team cognition research has predominantly relied on static measures of team cognition, with cognitive constructs as well as outcome measures being assessed at a single point in time. Yet, particularly in environments where team members have to adapt regularly to changing environmental contingencies, team cognition is likely to be characterized as an unfolding process, as teams adapt their cognitive structures to the changing demands of their task environment (Randall et al., 2011; Uitdewilligen, Waller, \& Pitariu, 2013). Little is known about how these emergent processes unfold over time.

Acknowledging the gap in the literature, scholars have started to pay attention to the cognitive dynamics underlying a team's responsiveness to the demands of a new or changing environment. To capture some of these recent developments, this special issue offers a state-ofthe-art selection of studies in this area. In this introductory article, we first provide a brief summary of the research field and continue with a short overview of the studies brought together in this special issue. Subsequently, we identify directions for future research on the dynamics of team cognition and team adaptation with the objective to inspire other researchers to further develop our understanding of the topic.

\section{TEAM COGNITION AND TEAM ADAPTABILITY: A BRIEF OUTLINE OF THE FIELD}

Since the turn of the century, team adaptation has become an increasingly prominent topic in team

\footnotetext{
Correspondence should be addressed to Josette M. P. Gevers, Human Performance Management Group, Department of Industrial Engineering and Innovation Sciences, Eindhoven University of Technology, Eindhoven, The Netherlands. E-mail: j.m.p.gevers@tue.nl

No potential conflict of interest was reported by the authors.
} 
literature, one that has been approached from several different angles. Whereas some have focused on a team's adaptability or adaptive capacity as an input to the team process (Randall et al., 2011), others have focused on team adaptive performance as an outcome of the team process (Chen, Thomas, \& Wallace, 2005). However, in most theoretical papers (Baard, Rench, \& Koslowski, 2014; Kozlowski, Gully, Nason, \& Smith, 1999; LePine, 2005; Rosen et al., 2011), it has been emphasized that team adaptation is a dynamic process in which "a change in team performance, in response to a salient cue or cue stream, leads to a functional outcome for the entire team" (Burke et al., 2006, p. 1190). Burke et al. (2006), for example, have conceptualized team adaptation as an emergent phenomenon that compiles over time from the unfolding of a recursive cycle of processoriented phases (i.e., situation assessment, plan formulation, plan execution, and team learning), whereby one or more team members use their resources to functionally change current cognitive or behavioural goal-directed action or structures to meet expected or unexpected demands. In this process, the team gathers and interprets task-relevant cues from the environment and assigns meaning to the perceived cues (patterns) based on existing knowledge structures. This information is then used to determine a course of action, which is enacted during plan execution. Finally, the team reflects on past events to learn from their experiences and facilitate future adaptation cycles.

Team cognitive structures play a central role in this model in that they function as both proximal outcomes and inputs of the adaptation processes. That is, each of the processes described above is believed to result in emergent cognitive states (i.e., shared mental models, team situation awareness, and team transactive memory), which subsequently function as input for the next phase. Although a number of studies have shown a relationship between a team's cognitive states and its ability to successfully deal with unexpected events (e.g., Randall et al., 2011; Ren, Carley, \& Argote, 2006; Waller, 1999), the dynamics of these relations are poorly understood (Baard et al., 2014). For instance it is likely that team members should change and update their mental models in response to changing circumstances (Uitdewilligen et al., 2013), but it is unclear which aspects of team cognition are most crucial in the different phases of team adaptation (Burke et al., 2006). Moreover, intervention studies are needed to provide rigid tests of causal relations and for providing practical suggestions for improving teams' adaptive capacity. The studies brought together in this special issue contribute to resolving these and other issues, putting a premium on moving beyond the statics to a more dynamic approach towards understanding team cognition and team adaptation.

\section{OVERVIEW OF THE SPECIAL ISSUE}

With the increased attention to team adaptation in the literature, a wealth of knowledge has been accumulated. At the same time, the field is plagued by a lack of consistency in the conceptualization and operationalization of the phenomenon of interest. In the first contribution to this special issue, Maynard and colleagues (2015) provide an overview of the team adaptation research (thereby also distinguishing team adaptation from related constructs such as team learning, reflexivity, creativity, and innovativeness) and develop a process-oriented (i.e., input-process-output) framework for understanding team adaptation. Central to their work is the notion that the nature of the adaptation process depends on the type and severity of the trigger. They suggest that different types of adaptation triggers (i.e., teamwork or taskwork-based) may call for adjustments in different adaptation content areas (i.e., action, interaction, or transition processes), which may, subsequently, affect a broad spectrum of adaptive outcomes including team emergent states, performance, and satisfaction.

The special issue then continues with empirical work. Reflecting the broadness of the team adaptation research field, these empirical works touch upon various combinations of cognitive, behavioural, and, to a lesser extent, affective processes involved in team adaptation. The first set of studies all addresses the emergence and effects of cognitive structures in teams facing some ambiguous and dynamic situation demanding an adaptive response. In a field study among 55 R\&D teams, Reuveni and colleagues (2015) identify team mental models as a supporting mechanism for innovation in professionally heterogeneous teams. Interestingly, their study shows that higher levels of professional heterogeneity are associated with higher levels of shared team mental models, but only under conditions of low transformational leadership. According to the authors, the presence of a transformational leader interferes with the natural interaction patterns that team members would otherwise engage in to get to know each other better, which impedes the development of a shared team mental model within the team.

Mohammed and colleagues (2015) go beyond the traditionally studied teamwork and taskwork domains and introduce the notion of temporal team mental models to explicitly include time-related aspects in mental model research. They conducted a laboratory study involving 98 three-person teams in a crisis management simulation to assess the performance effects of temporal team mental models over time. Their study supports the added value of sharing temporal mental models over and above team and task mental models for teams operating in a crisis situation, with temporal mental models developed later in the team's life exerting a stronger influence on team performance than those that were formed early. 
Moreover, the study introduces two successful methodologies for tapping objective similarity in team members' temporal mental models.

The study of Santos and colleagues (2015) also shows the importance of sharing temporal mental models for team performance. In a longitudinal study of 67 teams performing in a dynamic management simulation, they test the interactive effects of team learning behaviours and task, team, and temporal mental model similarity on performance improvement. They find that engaging in team learning behaviours only leads to performance improvement when teams have similar task and temporal mental models, suggesting that team cognitive structures are fundamental for team learning behaviours and performance improvement over time.

Oertel and Antoni (2015) also address team learning behaviours in relation to team cognition, but they focus on transactive memory development rather than on shared mental model development. Distinguishing between the different phases of a team's lifecycle, they show that knowledge-based learning behaviours (i.e., storage and retrieval) predict transactive memory development in the early stages, whereas communicationbased learning behaviours (i.e., reflection and co-construction) play a more important role in later stages of the team's life.

Bourbousson, R'Kiouak, and Eccles (2015) use a cued recall technique combined with dynamic social network analyses to describe changes in patterns of shared awareness within two basketball teams. They find members of an expert team to have less awareness of other team members than members of a novice team, suggesting that the experts are more parsimonious in their distribution of awareness. However, their dynamic analysis also shows within-team transitions in the team members' scope of awareness, which may be indicative of teams' ability to adapt to sudden perturbations. Their innovative methods for measuring and analysing the dynamics of situation awareness have a great potential in enhancing our understanding of the temporal dynamics of team cognition.

Focusing on the emergence of behavioural rather than cognitive processes, Schmutz, Hoffman, Heimberg, and Manser (2015) investigate the effectiveness of three team coordination behaviours (i.e., task distribution, closed loop communication, and providing information without requests) for clinical performance in a high-fidelity in situ medical emergency simulation study. In line with the theoretical assumptions proposed by Maynard et al. (2015), their study illustrates the importance of considering the impact of the task type in studying team coordination behaviours. More specifically, they found that closed-loop communication predicted clinical performance in algorithm-driven tasks (in which signals are obvious and performance is based on engaging in predefined algorithms and learned procedures as quickly as possible), but not in knowledge-driven tasks (in which diffuse cues from the scene must be integrated with existing knowledge to arrive at a diagnosis). Task distribution and providing information without requests did not contribute to clinical performance in either task type.

The three final contributions to this special issue each address the impact of a particular team intervention aimed at improving team adaptation. Konradt, Schippers, Garbers, and Steenfatt (2015) examine the separate and combined effects of guided team reflexivity and team feedback on team performance improvements in teams working together either face to face or virtually. The findings of the laboratory experiment involving 98 three-person student teams suggest that a combination of guided reflexivity and team feedback was the most effective way of stimulating team reflection, which significantly predicted team performance improvement. Moreover, detailed mediational analyses indicated that the effect of team reflection on team performance improvement was sequentially mediated by team mental models, task mental models, and team adaptation.

Sander, van Doorn, van der Pal, and Zijlstra (2015) study the impact of standardized communication protocols in 20 three-person teams facing an unexpected partial system failure during the performance of a lab-based dynamic team task. They found that the system failure was followed by a performance drop and gradual performance recovery in all teams, irrespective of the experimental condition, but that the drop was substantially smaller and the recovery substantially faster for teams with accurate mental models. Mental model similarity, on the other hand, showed no effects.

Finally, Ellwart and colleagues (2015) report on a laboratory-based test of a structured online team adaptation intervention (STROTA) to combat information overload in virtual teams. The study involved 63 virtual teams involved in a hidden-profile decision-making task. The intervention, which is based on a three-step algorithm of 1) individual situation awareness, 2) team situation awareness, and 3) plan formulation, proved to reduce subjective as well as objective information overload. According to the authors, the intervention facilitates the effective updating of team mental models, resulting in more coordinated and focused information exchange thereafter.

\section{WHAT'S NEXT?}

Together these studies represent some of the most recent developments towards a greater understanding of how team-related, task-related, and time-related aspects influence the emergence and development of cognitive structures and their impact on team adaption processes and outcomes. At the same time, we cannot deny that many areas are still open for further exploration and that there are several research needs that future studies could address to bring the field forward. First, we identify that there is a need for more conceptual clarity in 
adaptation research as well as a need for more sophisticated, fine-grained, but easy-to-use measurement techniques to capture changes in team cognition over time. Furthermore, we see a need for more research that takes notice of the wider contextual environment influencing adaptation dynamics. Finally, there is a need for a larger evidence base for interventions aimed at improving teams' adaptive capacity. At the same time, however, we also realize that there are boundaries to the possibilities for improvement in that too much adaptation may come to be dysfunctional, and that these boundaries, too, deserve to be further explored. We will now discuss each of these research needs in more detail.

One of the most prominent issues stifling the development of our understanding of the adaptation construct is the lack of consistency in conceptualizations and approaches. Baard, Rench and Kozlowski (2014) identify four distinct theoretical approaches to individual and team-level adaptation: adaptation as (a) a performance construct; (b) an individual difference construct; (c) a change in performance; and (d) an iterative, emergent process. According to the authors there are research gaps that call for progress in each of these approaches, but most prominent is the need for further integration between approaches. They suggest that further integration requires that researchers conceptualize adaptation in terms of a) the specific drivers for adaptation (i.e., what is it that requires adaptation), b) the focal level of the adaptation phenomenon (i.e., individual, team, unit, organization, trans-organizational), and c) the specific mechanisms underlying adaptive performance (i.e., cognitive, motivationalaffective, and behavioural mechanisms). The review of Maynard and colleagues (2015) provides an important step forward in solving some of the confusion and inconsistencies in terminology indicated by Baard et al. (2014). However, the number of studies that combine concepts from these different approaches is still very limited. In particular we still need more comprehensive, longitudinal studies that include factors related to teams' ability to adapt, as well as variables that depict the process of adaptation, and variables that track the changes in team outcomes over time. This would also aid further integration of team cognition, team learning, and team adaptation literatures, which (as we also learn from this issue) have largely been developed in separation, whereas further integration could greatly advance our understanding of adaptation as a multi-level, emergent phenomenon.

Another area that deserves special attention concerns the measurement of team cognition. Although team cognition has been conceptualized as an emergent phenomenon, it has rarely been studied as such. According to Kozlowski, Chao, Grand, Braun, and Kuljanin (2013), multi-level emergent phenomena originate at a lower level and emerge as a collective phenomenon, are process oriented, and are temporally sensitive, i.e., they take time to change and develop. Most empirical studies have measured team cognition (e.g., shared mental models, transactive memory systems) only at a single point in time (Kozlowski \& Chao, 2012) and the research focus has been on the emerged construct and not on the process of emergence itself. Yet, when a team needs to adapt to changing circumstances, it is likely to be the dynamic ability to update the knowledge structures that is most crucial for effective adaptation (Uitdewilligen et al., 2013). Therefore, if we truly aim to study the emergence of team cognition and its dynamic adjustment in response to external changes, we will need measures that allow for testing fine-grained changes in team cognition over time, without overburdening respondents. For instance, by measuring temporal mental models at two different time points, Mohammed and colleagues (2015) were able to show that similarity in temporal mental models is not particularly essential early in a team's life cycle, but exerts a stronger effect on team performance later in its development. Similarly, because Oertel and colleagues (2015) measured transactive memory systems repeatedly over a longer period of time, they were able to identify the phase-specific influences of team learning behaviours on transactive memory development. A number of recent studies provide promising new perspectives of what is possible in measuring and analysing the dynamics of cognition. For instance, McComb, Kennedy, Perryman, Warner, and Letsky (2010) captured the mental model convergence process by examining team communication over time. Bourbousson and colleagues (2015) introduce a method for assessing the dynamics of team cognition using video recordings of team activity in combination with postactivity interviews data. Additional ideas for developing such methods are likely to come from related fields. For instance, content analysis may be applied to archival data sources, such as e-mail correspondence and workflow systems to track changes in team cognition over time (e.g., Bligh, Kohles, \& Meindl, 2004). Hence, we invite researchers to be open to and experiment with new methods for gathering and analysing team cognition data.

Furthermore, it is evident that team adaptation cannot be assumed to occur in a vacuum, and our models of team adaptation should include the complex interactions occurring when teams adjust to their environment. Teams are not isolated entities; they are open systems, embedded within a context, and they interact with, influence, and are influenced by (characteristics of) that context (Arrow, McGrath, \& Berdahl, 2000). The contributions to this special issue by Maynard et al. (2015) and Schmutz et al. (2015) both emphasize how important it is to consider the team task and how characteristics of that task may place specific requirements on a team's adaptive response. Moreover, teams often depend on other individuals, teams, and organizations that are operating within the same context, such as when 
multiple teams are working together on a common overall goal (Marks, DeChurch, Mathieu, Panzer, \& Alonso, 2005). Because the activities in such multi-team systems must be mutually coordinated, a change in one team will often require a consequential adaptation in the other teams. Moreover, given that organizational members may have rather stringent convictions of how "things are done" (Prahalad \& Bettis, 1986), team adaptation may not only entail adapting the cognitive structures within the team, but also challenge the assumptions held in the wider contextual environment. This implies that team adaptation research may benefit from adopting an external and boundary spanning perspective (e.g., Choi, 2002; Kouchaki, Okhuysen, Waller, \& Tajeddin, 2012; Marrone, 2010) that takes into account how team adaptation occurs as a complex multi-level process in which the team is impacted by as well as impacts its environment.

An important practical question is how we can translate the existing knowledge into practical interventions that help teams become adaptive. Several studies in this issue provide guidelines that can help practitioners build trainings and other tools for developing adaptive teams (Ellwart et al., 2015; Sander et al., 2015; Konradt et al., 2015). For instance, Ellwart and colleagues (2015) emphasize the importance of helping members of virtual teams to cope with information overload and they provide a structured online procedure that enables teams to effectively cope with this. Another promising line of research focuses on how and under what conditions guided team reflexivity can help teams make sense of and learn from unexpected events (Gurtner, Tschan, Semmer, \& Nägele, 2007; Konradt et al., 2015). Initial evidence suggests that iterative cycles of action and reflection, for instance formalized in after-actionreviews, enable teams to learn from previous experiences and translate this into the adaptive capacity to successfully manage future events (Vashdi, Bamberger, \& Erez, 2013). However, because randomized experimental studies that explicitly test interventions aimed at enlarging teams' adaptive capacity in the field are scarce, more of such studies are needed to bridge the research-practitioner gap.

Then again, we have to acknowledge that there may be boundaries to the possibilities for improvement and that team adaptation may not always be beneficial. Extant research, including the findings presented in this issue, leaves little doubt as to how important team learning and team adaptation is for the effectiveness of teams operating in unpredictable, complex, and turbulent environments. At the same time, though, researchers (e.g., Bunderson \& Sutcliffe, 2003; Wiedow \& Konradt, 2011) have warned against placing too much emphasis on learning and adaptation. Learning efforts consume valuable resources without the assurance of results (Edmondson, 1999) and the benefits of exploring new ideas and initiatives may not always outweigh the costs. Santos et al. (2015), for example, showed that, in the absence of mental model similarity, engagement in team learning processes actually impeded performance improvement. Experimenting with new activities and approaches in pursuit of continuous improvement may unnecessarily detract from performance and compromise performance efficiency. Especially high-performing teams may actually be more likely to continue their pattern of high performance by simply doing what they have done before, unless conditions change substantially. Wiedow and Konradt (2011) have suggested that the relationship between team adaptation and team effectiveness may actually be a curvilinear one, as reflection and adaptation may initially improve performance, but may eventually begin to undermine team performance. Therefore, another important question for future research to answer is under what circumstances and to what extent teams should actually engage in processes of team learning and adaptation, and how we may avoid dysfunctional team adaptation.

In sum, this Special Issue on the dynamics of team cognition and team adaptation brings us many valuable insights, but also reveals that there are still plenty of possibilities for future contributions. We hope that the current collection of papers will be a valuable resource to scholars interested in team cognition and team adaption, and that it will inspire at least some to take on the challenge of further exploring and clarifying this fascinating and important research theme.

\section{ORCID}

Sjir Uitdewilligen (D) http://orcid.org/0000-0001-7815-1579 Ana M. Passos (D) http://orcid.org/0000-0003-4966-4468

\section{REFERENCES}

Arrow, H., McGrath, J. E., \& Berdahl, J. L. (2000). Small groups as complex systems: Formation, coordination, development, and adaptation. Thousand Oaks, CA: Sage Publications.

Baard, S. K., Rench, T. A., \& Kozlowski, S. W. (2014). Performance adaptation: A theoretical integration and review. Journal of Management, 40, 48-99. doi:10.1177/0149-2063.13.48.8210

Bligh, M. C., Kohles, J. C., \& Meindl, J. R. (2004). Charting the language of leadership: A methodological investigation of President Bush and the crisis of 9/11. Journal of Applied Psychology, 89, 562-574. doi:10.1037/0021-9010.89.3.562

Bourbousson, J., R'Kiouak, M., \& Eccles, D. W. (2015). The dynamics of team coordination: A social network analysis as a window to shared awareness. European Journal of Work and Organizational Psychology, 24, 717-735. doi:10.1080/1359432x.2014.1001977

Bunderson, J. S., \& Sutcliffe, K. M. (2003). Management team learning orientation and business unit performance. Journal of Applied Psychology, 88, 552-560. doi:10.1037/0021-9010.88.3.552

Burke, C. S., Stagl, K. C., Salas, E., Pierce, L., \& Kendall, D. (2006). Understanding team adaptation: A conceptual analysis and model. Journal of Applied Psychology, 91, 1189-1207. doi:10.1037/00219010.91.6.1189 
Chen, G., Thomas, B., \& Wallace, J. C. (2005). A multilevel examination of the relationships among training outcomes, mediating regulatory processes, and adaptive performance. Journal of Applied Psychology, 90, 827-841. doi:10.1037/00219010.90 .5827

Choi, J. N. (2002). External activities and team effectiveness review and theoretical development. Small Group Research, 33, 181-208. doi:10.1177/104649640203300202

DeChurch, L. A., \& Mesmer-Magnus, J. R. (2010). The cognitive underpinnings of effective teamwork: A meta-analysis. Journal of Applied Psychology, 95, 32-53. doi:10.1037/a0017328

Edmondson, A. (1999). Psychological safety and learning behavior in work teams. Administrative Science Quarterly, 44, 350-383. doi: $10.2307 / 2666999$

Ellwart, T., Happ, C., Gurtner, A., \& Rack, O. (2015). Managing information overload in virtual teams: Effects of a structured online team adaptation on cognition and performance. European Journal of Work and Organizational Psychology, 24, 661-675. doi:10.1080/ 1359432x.2014.1000873

Gurtner, A., Tschan, F., Semmer, N. K., \& Nägele, C. (2007). Getting groups to develop good strategies: Effects of reflexivity interventions on team process, team performance, and shared mental models. Organizational Behavior and Human Decision Processes, 102, 127-142. doi:10.1016/j.obhdp.2006.05.002

Konradt, U., Schippers, M., Garbers, Y., \& Steenfatt, C. (2015). Effects of guided reflexivity and team feedback on team performance improvement: The role of team regulatory processes and cognitive emergent states. European Journal of Work and Organizational Psychology, 24, 736-754. doi:10.1080/ 1359432x.2015.1005608

Kouchaki, M., Okhuysen, G. A., Waller, M. J., \& Tajeddin, G. (2012). The treatment of the relationship between groups and their environments: A review and critical examination of common assumptions in research. Group \& Organization Management, 37, 171-203. doi:10.1177/1059601112443850

Kozlowski, S., Chao, G., Grand, J., Braun, M. T., \& Kuljanin, G. (2013). Advancing multilevel research design: Capturing the dynamics of emergence. Organizational Research Methods, 16, 581-615. doi:10.1177/1094428113493119

Kozlowski, S. W. J., \& Chao, G. T. (2012). The dynamics of emergence: Cognition and cohesion in work teams. Managerial and Decision Economics, 33, 335-354. doi:10.1002/mde.2552

Kozlowski, S. W. J., Gully, S. M., Nason, E. R., \& Smith, E. M. (1999). Team compilation: Development, performance, and effectiveness across levels and time. In D. R. Ilgen \& E. D. Pulakos (Eds.), The changing nature of work performance: Implications for staffing, personnel actions, and development (pp. 240-292). San Francisco, CA: Jossey Bass.

Kozlowski, S. W. J., \& Ilgen, D. R. (2006). Enhancing the effectiveness of work groups and teams. Psychological Science in the Public Interest, 7, 77-124. doi:10.1111/j.1529-1006.2006.00030.x

LePine, J. A. (2005). Adaptation of teams in response to unforeseen change: Effects of goal difficulty and team composition in terms of cognitive ability and goal orientation. Journal of Applied Psychology, 90, 1153-1167. doi:10.1037/0021-9010. 90.6.1153

Marks, M. A., DeChurch, L. A., Mathieu, J. E., Panzer, F. J., \& Alonso, A. (2005). Teamwork in multiteam systems. Journal of Applied Psychology, 90, 964-971. doi:10.1037/0021-9010.90.5. 964

Marrone, J. A. (2010). Team boundary spanning: A multilevel review of past research and proposals for the future. Journal of Management, 36, 911-940. doi:10.1177/0149206309353945

Mathieu, J., Maynard, M. T., Rapp, T., \& Gilson, L. (2008). Team effectiveness 1997-2007: A review of recent advancements and a glimpse into the future. Journal of Management, 34, 410-476. doi:10.1177/0149206308316061

Maynard, M. T., Kennedy, D. M., \& Sommer, S. A. (2015). Team adaptation: A fifteen-year synthesis (1998-2013) and framework for how this literature needs to "adapt" going forward. European Journal of Work and Organizational Psychology, 24, 676-701. doi:10.1080/1359432x.2014.1001376

McComb, S., Kennedy, D., Perryman, R., Warner, N., \& Letsky, M. (2010). Temporal patterns of mental model convergence: Implications for distributed teams interacting in electronic collaboration spaces. Human Factors: The Journal of the Human Factors and Ergonomics Society, 52, 264-281. doi:10.1177/ 0018720810370458

Mohammed, S., Hamilton, K., Tesler, R., Mancuso, V., \& McNeese, M. (2015). Time for temporal team mental models: Expanding beyond "What" and "How" to incorporate "When". European Journal of Work and Organizational Psychology, 24, 787-803. doi:10.1080/ $1359432 \times .2015 .1024664$

Oertel, R., \& Antoni, C. (2015). Phase-specific relationships between team learning processes and transactive memory development. European Journal of Work and Organizational Psychology, 24, 645-660. doi:10.1080/1359432x.2014.1000872

Prahalad, C. K., \& Bettis, R. A. (1986). The dominant logic: A new linkage between diversity and performance. Strategic Management Journal, 7, 485-501. doi:10.1002/smj.4250070602

Randall, K. R., Resick, C. J., \& DeChurch, L. A. (2011). Building team adaptive capacity: The roles of sensegiving and team composition. Journal of Applied Psychology, 96, 525-540. doi:10.1037/a0022622

Ren, Y., Carley, K. M., \& Argote, L. (2006). The contingent effects of transactive memory: When is it more beneficial to know what others know? Management Science, 52, 671-682. doi:10.1287/ mnsc. 1050.0496

Reuveni, Y., \& Vashdi, D. R. (2015). Innovation in multidisciplinary teams: The moderating role of transformational leadership in the relationship between professional heterogeneity and shared mental models. European Journal of Work and Organizational Psychology, 24, 702-716. doi:10.1080/1359432x.2014.1001377

Rico, R., Sánchez-Manzanares, M., Gil, F., \& Gibson, C. (2008). Team implicit coordination processes: A team knowledge-based approach. Academy of Management Review, 33, 163-184. doi:10.5465/AMR.2008.27751276

Roe, R. A., Gockel, C., \& Meyer, B. (2012). Time and change in teams: Where we are and where we are moving. European Journal of Work and Organizational Psychology, 21, 629-656. doi:10.1080/ 1359432X.2012.729821

Rosen, M. A., Bedwell, W. L., Wildman, J. L., Fritzsche, B. A., Salas, E., \& Burke, C. S. (2011). Managing adaptive performance in teams: Guiding principles and behavioral markers for measurement. Human Resource Management Review, 21, 107-122. doi:10.1016/j. hrmr.2010.09.003

Sander, P., van Doorn, R., van der Pal, J., \& Zijlstra, F. (2015). Team adaptation to an unforeseen system failure: Limits of the potential aids of shared knowledge and standardized communication. European Journal of Work and Organizational Psychology, 24, 755-770. doi:10.1080/1359432x.2015.1006199

Santos, C., Uitdewilligen, S., \& Passos, A. M. (2015). A temporal common ground for learning: The moderating effect of shared mental models on the relation between team learning behaviours and performance improvement. European Journal of Work and Organizational Psychology, 24, 804-819. doi:10.1080/1359432x. 2015.1049158

Schmutz, J., Hoffman, F., Heimberg, E., \& Manser, T. (2015). Effective coordination in medical emergency teams: The moderating role of task type. European Journal of Work and Organizational Psychology, 24, 771-786. doi:10.1080/1359432x.2015.1018184 
Uitdewilligen, S., Waller, M. J., \& Pitariu, A. H. (2013). Mental model updating and team adaptation. Small Group Research, 44, 127-158. doi:10.1177/1046496413478205

Vashdi, D. R., Bamberger, P. A., \& Erez, M. (2013). Can surgical teams ever learn? The role of coordination, complexity, and transitivity in action team learning. Academy of Management Journal, 56, 945-971. doi:10.5465/amj.2010.0501
Waller, M. J. (1999). The timing of adaptive group responses to nonroutine events. Academy of Management Journal, 42, 127-137. doi: $10.2307 / 257088$

Wiedow, A., \& Konradt, U. (2011). Two-dimensional structure of team process improvement: Team reflection and team adaptation. Small Group Research, 42, 32-54. doi:10.1177/10464964 10377358 